\title{
EXPERIENCES AND CHALLENGES IN FOSTERING INDUSTRY AND UNIVERSITY COLLABORATIONS
}

Focus Group - 1

Mikko Ruohonen (Finland, Chair), Peter Normak, (Estonia, Rapporteur), Barrie Thompson (UK, Rapporteur), John Bentley (Australia), Till Becker (Germany), Maria Nakayama (Brazil), Rod Turner (Australia), Lu Xi Yan (China), Cindy Zhu Bin (China)

Key words: Industry, University, Higher Education, Exchange, Collaboration, Projects.

\section{ORGANISATION AND PARTICIPATION}

Six sessions were devoted to Focus Group activities during the conference week. These consisted of four working sessions (each of 90 minutes duration) for the nominated participants, a poster session (timetabled between the second and third working sessions) to which all conference delegates were invited, and a formal reporting session to all the delegates during the last afternoon session of the conference. The poster session provided an opportunity to get wider feedback on the Focus Group's initial proposals and an exchange of ideas. In addition to notes taken during the workshop, sound recordings were made of the majority of the sessions. Also, a photographic record was made of both the posters and white board diagrams produced during the working sessions. It is hoped that when resources allow, the recordings can be transcribed and a more detailed account of the group's discussions produced.

The remainder of this report is organised as follows. Sections 2 and 3 provide high-level summaries of the first two working sessions of the Focus 
Mikko Ruohonen (Finland, Chair), Peter Normak, (Estonia, Rapporteur), Barrie Thompson (UK, Rapporteur), John Bentley (Australia), Till Becker (Germany), Maria Nakayama (Brazil), Rod Turner (Australia), Lu Xi Yan (China), Cindy Zhu Bin (China)

Group. Section 4 reports on the poster session. Section 5 provides a summary of the second two working sessions. Finally section 6 reports the groups overall findings and recommendations as presented on the final day of the conference.

\section{SESSION 1: THEME, TOPICS, AND EXPERIENCES}

The first of the Focus Group's working sessions took place on the first day of the conference. It began with participant introductions and the chair setting the overall theme for the Focus Group:

\section{University and Industry Collaboration and its Effects on Education}

The chair then identified and spoke briefly on three particular topic areas that he encouraged the group to consider during the remainder of their meetings. These were:

- Experiences that they had had relating to University and Industry collaboration.

- Challenges and problems that could be identified in University and Industry collaborations.

- Action plans to solving problems and addressing challenges.

The chair also provided the attendees with support material in the form of a paper by Jarvinen and Poikela (2001) which addressed learning at work. The group then had a general discussion on the issues raised by the chair. This was then followed by short participant experience reports covering particular situations in: Estonia, UK, Australia, and Germany.

\section{SESSION 2: LINKS BETWEEN UNIVERSITIES AND INDUSTRY}

The second working session took place during the second afternoon of the conference. It commenced with further consideration of individual experiences of University and Industry collaborations. The group then started to look at more general issues and different dimensions such as issues relating to: Undergraduate, Postgraduate/Research, National Government, and Local/Regional Government. The group also collaborated in producing 
models and representations on the meeting room white boards as shown in figures 1 and 2.

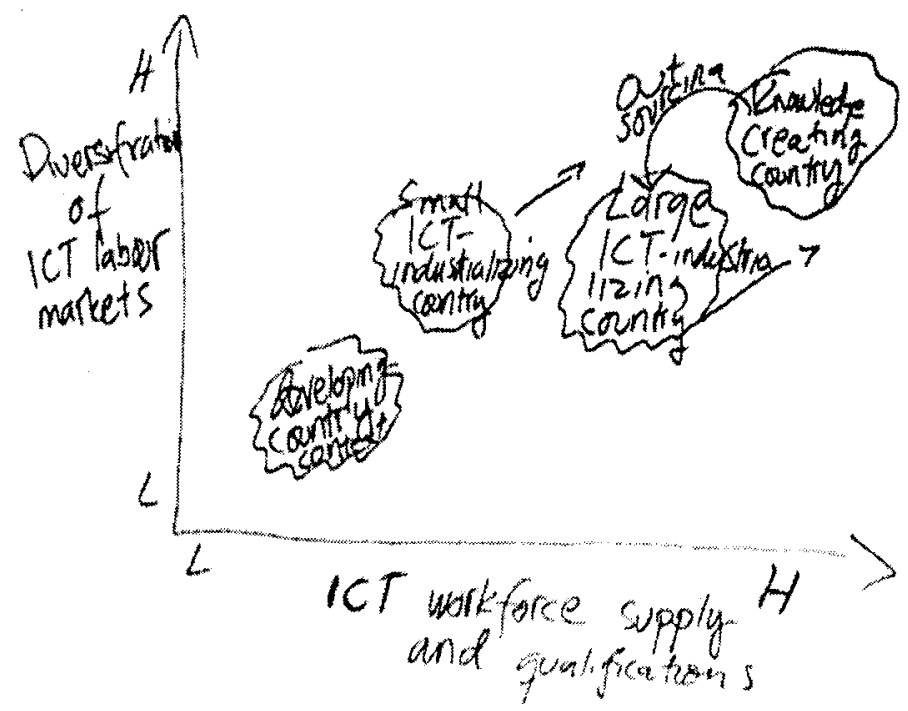

Figure 1 The diversification of ICT labour markets vs. ICT workforce supply and qualifications

These were then converted into a set of posters that incorporated the model shown in figure. 1, a list of challenges, and possible solutions relating to:

- Staff and knowledge exchange.

- Competence marketing/management.

- National development involvement. 
Mikko Ruohonen (Finland, Chair), Peter Normak, (Estonia, Rapporteur), Barrie Thompson (UK, Rapporteur), John Bentley (Australia), Till Becker (Germany), Maria Nakayama (Brazil), Rod

Turner (Australia), Lu Xi Yan (China), Cindy Zhu Bin (China)

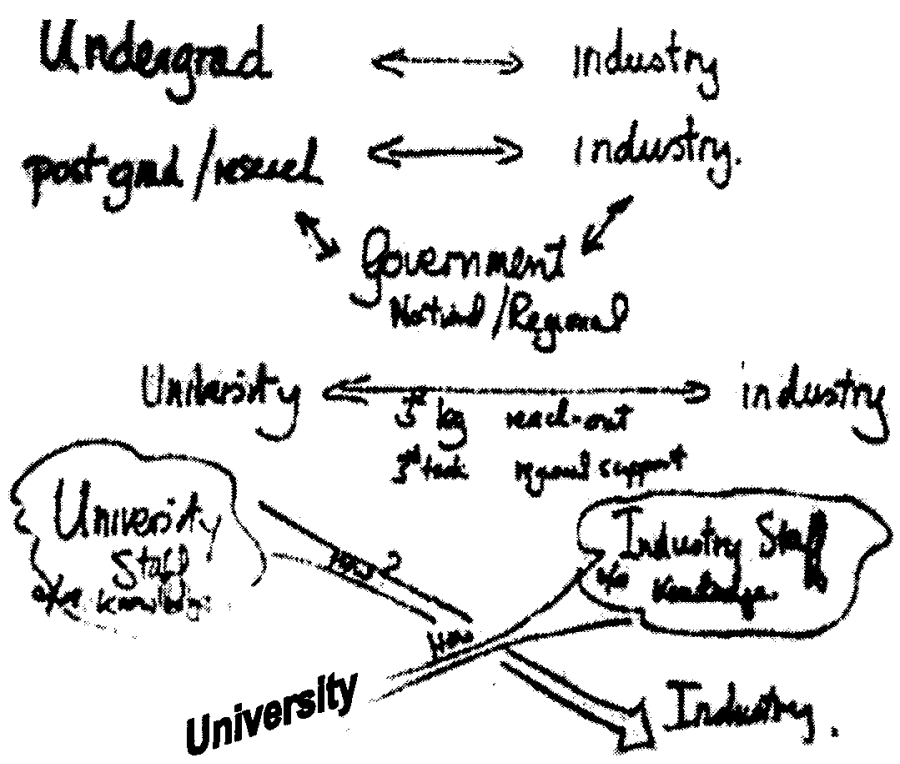

Figure 2 University and Industry Links

\section{THE POSTER SESSION}

This took place at the end of the second day after the formal presentation sessions. It gave the delegates the opportunity to see what the other Focus Groups had been working on, discuss the topics/issues highlighted, and provide formal comments in the form of Post-Its fixed to the posters. The comments received relating to improving University and Industry links were:

- (Academics should) get in contact with companies, offer solutions for companies problems, develop CRM.

- (Academics should) build up industry competence.

- (Academic) staff (should) work with industry on formulating criteria for the real-life problems the students are working on.

- University (should encourage) "Start-up Businesses", "Technology Transfer.

- Adopt "work" processes from each other - (with the aim of reaching) the same process in both.

- (and that both should) go for the "primary" process. 


\section{GROUP SESSIONS 3 AND 4: REFLECTIONS}

A short session at the start of the third day of the conference was used to reflect on the feedback and comments received at the poster session. The longer session at the end of the fourth day was used to reflect on all that had been covered and the models that had been developed and decide on what would be reported in the final presentation session. When the group revisited the model depicted in figure 1, which has as axes - the diversification of ICT labour markets and ICT workforce supply and qualifications, another factor became apparent. The model had been derived from consideration of the interactions between Universities and Industry and the roles of National/Local/Regional Government. However, what now became clear was that in the earlier discussions the group had omitted to consider the effects that professional and accrediting bodies could have on University and Industry interactions. Thus a much more sophisticated model needs to be developed (scope for a future Focus Group?).

\section{GROUP PRESENTATION: OVERALL FINDINGS AND RECOMMENDATIONS}

The presentation to the assembled delegates on the last afternoon commenced with a brief overview of the process the group had adopted and the models that had been derived. The group's conclusions and recommendations regarding improving University and Industry interactions were then reported as follows:

\section{Staff and Knowledge Exchange}

- Sabbaticals in industry

- Best practice examples:

Lessons learned

Ways to exchange

Industry solutions explicitly for teachers

- Student involvement with industry criteria, placements, fieldwork

- Alumni activities

\section{Competence Marketing/Management}

- Joint organization of conferences, "fireplace talks", seminars.

- Calls for company supervisors

- "Going out" for business meetings

- Professional bodies, memberships/collaborations/accreditation 

Rapporteur), Barrie Thompson (UK, Rapporteur), John Bentley (Australia), Till Becker (Germany), Maria Nakayama (Brazil), Rod Turner (Australia), Lu Xi Yan (China), Cindy Zhu Bin (China)

- Incubation/start-up business promotion

\section{National Development Involvement}

- Affecting decision making (such as information society programmes)

- General publicity

- Specialized, coordinated funding applications

\section{Proactive Policy Making}

- Getting the voice to (ear of) government

- Committee working

- Participating in policy paper planning

- Legislation initiatives

- Funding bodies

However there is a problem:

Professional and Accrediting Bodies: WHERE DO THESE FIT IN?

\section{SUPPORT MATERIAL}

Jarvinen A. and Poikela E. (2001) Modelling reflective and contextual learning at work, Journal of Workplace Learning, Vol. 13, No. 7/8, pp282-289. 